\title{
Interactive comment on "A post-wildfire response in cave dripwater chemistry" by Gurinder Nagra et al.
}

\section{A. Butturini (Editor)}

abutturini@ub.edu

Received and published: 24 March 2016

Dear Authors, I am pleased to inform you that I got the reviewer suggestions and comments. Reviewers had an excellent work and overall considered your manuscript an interesting and valuable contribution for HESS. I totally agree with them. However, as you will read from their comments, publication in its present form is not recommended, and a major revision is being requested. I really suggest to consider in detail the general, specific and technical Reviewer's suggestions/comments in order to improve your manuscript. Paid special attention to: i) Improve the writing ii) Reduce the speculative arguments; iii) Make a more consistent comparison to other caves to evaluate in more depth the eventual relevance of natural geochemical changes in drip waters. In your reply, it is essential to explaining how and where each point of the Reviewers' comments has been addressed. Should you disagree with any part of the reviews, please explain 
why. Finally, I want to thank Reviewers for their really competent work and in-depth constructive analysis that will strongly help the authors to improve their manuscript.

Interactive comment on Hydrol. Earth Syst. Sci. Discuss., doi:10.5194/hess-2016-1, 2016. 